\title{
Pancreatic Neuroendocrine Tumor cM1c TNM Finding v8
}

National Cancer Institute

\section{Source}

National Cancer Institute. Pancreatic Neuroendocrine Tumor CM1c TNM Finding v8. NCI Thesaurus. Code C135543.

Pancreatic neuroendocrine tumor with both hepatic and extrahepatic metastases. (from AJCC 8th Ed.) 